\title{
Features of Vegetative Homeostasis in Teenagers with Myopia
}

\author{
Sargylana Yu. Artamonova ${ }^{1, *}$, Aelita M. Ammosova ${ }^{1}$, Lena A. Stepanova ${ }^{1}$, \\ Nadezhda M. Zakharova ${ }^{1}$ and Sardana V. Markova ${ }^{1}$ \\ ${ }^{1}$ M.K. Ammosov North-Eastern federal university, Medical institute, 27, Oyunsky St., Yakutsk, 677000, Russia \\ *Corresponding author. Email: syu.artamonova@s-vfu.ru
}

\begin{abstract}
Myopia is one of the most relevant problems in pediatrics. One of the starting mechanisms of myopia is accommodation disorders. With an imbalance of autonomic innervation of the ciliary muscle, the process of accommodation is disrupted, which leads to the development and progression of myopia. The purpose of this study was to assess the features of vegetative homeostasis in teenagers with myopia. During the work, a survey was conducted among 300 teenagers of 15 years old, in schools of Yakutsk. The main group was 114 teenagers with myopia, the control group was 186 adolescents without refraction disorders. According to cardiorhythmography, teenagers with myopias have a high level of centralization of heart rate management, a relatively high level of activity of the sympathetic department of the autonomic nervous system and low activity indicators of the parasympathetic department of the autonomic nervous system. Sympathicotonia was much more common in young men than in girls. Sympathicotonia, functional tension and overvoltage, increased cardiovascular response to an orthostatic probe, excessive and insufficient, and paradoxical vegetative provision are characteristic of teenagers with myopia. The results showed that teenagers with myopia of both genders have autonomic nervous system imbalance.
\end{abstract}

Keywords: vegetative homeostasis, myopia, teenagers, pediatrics. Sympathicotonia, autonomic nervous system imbalance

\section{INTRODUCTION}

Myopia is one of the most relevant problems in pediatrics. According to studies over the past decade, there has been a significant increase in teenagers with myopia in the world.

The frequency of myopia spread varies significantly from country to country. Mostly, this type of refraction occurs in the countries of South-East Asia. According to some references, the spread of myopia comprises $90 \%$ there $[1,2]$. In Europe, myopia is less common; it exceeds $35 \%$ [3].

In some regions of Russia, $2.4 \%$ of children are already myopic when entering the first grade. By the fifth grade, the number of short-sighted children increases by 8 times, reaching $19.7 \%$. By the 11 th grade of school, the prevalence of myopia is approaching $36.8 \%[4,5]$.

World Health Organization's Programme for the Prevention of Blindness and Deafness2020 defines myopia as one of five priority diseases. An active prevention of avoidable blindness among these five diseases is required.

According to prognosis, the number of short-sighted will be 4.8 billion people by 2050 . This means that $49.8 \%$ of the world's population will be myopic. At the same time, almost 1 billion people will have myopia of a high degree [5]. Myopia increases the risk of developing early acquired cataracts, retinal ruptures, glaucoma. In this case, the early age of myopia is the most reliable factor in the development of high-grade myopia in the future $[1,3,7]$. 
The most significant factors leading to the development of myopia include aggravated heredity, connective tissue weakness, somatic diseases, poor nutrition, lack or insufficiency of solar insolation, sedentary lifestyle, intense visual load.

The imbalance of the autonomic (vegetative) nervous system is one of the factors in the development and progression of myopia. The autonomic nervous systemplays an essential role in the adaptation processes. As a functional imbalance of the autonomic innervation of the ciliary muscle occurs, the process of accommodation is disrupted. It leads to the development and progression of myopia [8].

Due to the high prevalence of myopia in teenagers, it is now of particular relevance to study the features of the autonomic nervous system in teenagers with refractive disorders in order to carry out measures to prevent them.

The purpose of the study is to determine the features of vegetative homeostasis in teenagers with myopia.

\section{METHODS AND MATERIALS}

During the work, a survey was conducted of 300 teenagers of 15 years old, schoolchildren of Yakutsk. The main group was 114 teenagers with myopia, the control group was 186 teenagers without refraction disorders. Ophthalmological examination included: visometry, refractometry (skiascopy), ophthalmoscopy.

Heart rate variability was studied with the CardioRhythmographic Computer Complex "Cardio Expert." During the work, the analysis of medical documentation was carried out by forms No. 026/y, 112/y, 63/y. Statistical processing was performed using the statistical analysis package "SPSS 20."

\section{RESULTS AND DISCUSSION}

According to our study, $38 \%$ showed a refractive disorder out of the total 300 examined teenagers. At the same time, the frequency of myopia in girls is higher compared to boys. The proportion of girls with myopias is $57 \%$, boys $-43 \%$. Analysis of the structure of refraction disorders in teenagers showed that the most common are grade I myopia - 56.1 \%. In second place in terms of prevalence was grade II myopia - $34.2 \%$. In third place is high-grade myopia, which was found in teenagers in $9.7 \%$ of cases.

From the analysis of the obtained data, it was revealed that on average the diagnosis of myopia was established for adolescents from 10 to 12 years old $67 \%$.

The development of myopia is usually associated with the beginning of schooling, but often it starts in preschool age. Before the age of 7 , this diagnosis was made in $9 \%$ of cases. It is these patients who have a more unfavorable prognosis of the course of the disease due to the increased risk of complications.

The assessment of the physical development of teenagers was carried out in the course of the study.

In order to study the factors which determine the formation of myopia, we used a questionnaire that contained various questions related toa lifestyle, heredity, leisure activities, etc. of young people.

Having assessed the physical development of young people we revealed that $66.7 \%$ of teenagers with refraction have normal physical development, while in the control group $-80.1 \%$.

Excess body weight was registered in the main group within $12.3 \%$ of young people, in the control group it equals to $5.9 \%$; body weight deficit is found in the main group $(21.0 \%)$, whereas in the control group it stands for $12.9 \%$. In general, teenagers with refraction errors are mostly underweight.

The hereditary factor greatly increases the probability of developing myopia. Thus, the risk of developing myopia in a child with one myopic parent is 2-3 times higher than in children whose parents do not have myopia. It is known that two myopic parents increase the possibility of developing myopia in a child by another 1.5-2 times [7]. According to our survey, $62.3 \%$ of young people also indicated the presence of myopia in parents and siblings.

Recent studies confirm that being in the open area reduces the risk of myopia [7]. Modern young people living in cities and towns have a low level of physical activity. Teenagers have PE classes two hours weekly. In majority, these PE lessons are held indoors because of harsh climatic conditions in winter. Most interviewers from both groups attend PE classes.

The data of teenagers' physical activity are presented in Table 1. The majority of them from both groups attend physical education classes at school. In addition to it, $50.6 \%$ of girls and $66.6 \%$ of boys from the control group participate in extracurricular sports activities (general physical training, athletics, swimming, freestyle wrestling, etc.). Also $30.8 \%$ of girls and $11.4 \%$ of boys from the control group are engaged in dance classes.

Only $38.5 \%$ of girls and $38.8 \%$ of boys from the main group participate in extracurricular sports activities. $15.4 \%$ of girls and $10.2 \%$ of boys take dance classes.

In the warm season, $41.6 \%$ of girls and $40.8 \%$ of boys from the main group go for a walk for 2 hours and more. $75.2 \%$ of girls and $67.6 \%$ of boys from the control group go on a walk outside for 2 hours and more either. According to the survey data, $9.2 \%$ of girls and 
$18.4 \%$ of boys have answered that they don't go for a walk at all. Therefore, the examined adolescents have lack of physical activity.

As a result of analysis of the questionnaire data, it has been noted that all teenagers with myopia actively use gadgets during the day. Only about $5.0 \%$ of adolescents with myopia and without refractive errors use gadgets less than 2 hours. On average, teenagers spend up to 6 hours a day in front of gadgets.

Table 1. Physical activity of teenagers

\begin{tabular}{|c|c|c|c|c|}
\hline & \multicolumn{2}{|c|}{\begin{tabular}{|l|} 
Main \\
group, \%
\end{tabular}} & \multicolumn{2}{|c|}{$\begin{array}{l}\text { Control } \\
\text { roup, \% } \\
\end{array}$} \\
\hline & girls & boys & girls & boys \\
\hline Physical education classes & 89.2 & 93.3 & 92.6 & 95.2 \\
\hline Sports activities & 38.5 & 38.8 & 50.6 & 66.6 \\
\hline Dance classes & 15.4 & 10.2 & 30.8 & 11.4 \\
\hline $\begin{array}{l}\text { Gadget usage (smartphones, } \\
\text { computers, tablets) } \\
1 \text { hourand less } \\
1-2 \text { hours } \\
2-3 \text { hours } \\
3-4 \text { hours } \\
4-5 \text { hours } \\
5-6 \text { hours } \\
6 \text { hours and more }\end{array}$ & \begin{tabular}{|l|}
1.5 \\
7.7 \\
7.7 \\
26.2 \\
23.0 \\
20.0 \\
13.8 \\
\end{tabular} & $\begin{array}{l}- \\
6.1 \\
8.2 \\
10.2 \\
36.7 \\
22.6 \\
16.3 \\
\end{array}$ & $\begin{array}{l}2.5 \\
4.9 \\
8.6 \\
45.7 \\
18.5 \\
11.1 \\
8.6 \\
\end{array}$ & $\begin{array}{l}2.8 \\
2.8 \\
10.5 \\
40.9 \\
24.7 \\
9.5 \\
8.6 \\
\end{array}$ \\
\hline $\begin{array}{l}\text { Preparation for classes/Reading } \\
\text { Less than } 1 \text { hour } \\
1-2 \text { hours } \\
3 \text { hours and more } \\
\text { Do not prepare/ read }\end{array}$ & $\begin{array}{l}- \\
0.5 \\
95.5 \\
- \\
\end{array}$ & $\begin{array}{l}10.2 \\
32.6 \\
55.1 \\
2.0\end{array}$ & $\begin{array}{l}2.5 \\
30.8 \\
62.9 \\
3.7 \\
\end{array}$ & $\begin{array}{l}16.2 \\
29.5 \\
45.7 \\
8.6\end{array}$ \\
\hline $\begin{array}{l}\text { Going for a walk } \\
\text { Do not go for a walk } \\
1 \text { hour } \\
2 \text { hours } \\
3 \text { hours and more }\end{array}$ & $\begin{array}{l}9.2 \\
49.2 \\
23.1 \\
18.5\end{array}$ & $\begin{array}{l}18.4 \\
40.8 \\
24.5 \\
16.3\end{array}$ & $\begin{array}{l}8.6 \\
16.0 \\
44.4 \\
30.8\end{array}$ & $\begin{array}{l}8.6 \\
23.8 \\
41.9 \\
25.7\end{array}$ \\
\hline
\end{tabular}

Moreover, the duration of the use of these devices among teenagers with moderate and high myopia is higher that of the group of teenagers with mild myopia.

Additionally, teenagers spend a lot of time preparing for classes. $95.5 \%$ of girls and $55.1 \%$ of boys from the main group, and $62.9 \%$ of girls and $45.7 \%$ of boys from the control group do it for 3 hours and more a day.

When young people with low vision do their hometasks they usually use only daylight $-51.6 \%$, only a desk lamp $-9.6 \%$, and both sources of light $-38.7 \%$.

As for the duration of sleep, it has been turned out that in the control group $64 \%$ of teenagers sleep 8-9 hours a day, $12.3 \%$ sleep $10-11$ hours, $23.7 \%$ sleep less than 8 hours. In the main group $55.2 \%$ of teenagers sleep 8-9 hours a day, $22.9 \%$ sleep 10-11 hours, $21.9 \%$ sleep less than 8 hours.

When being asked about their general state of health, young people from the control group assessed as following: almost healthy $-47 \%$, absolutely healthy -
$27.3 \%$ and not very healthy $-20.2 \%$. Among teenagers with visual impairments, only $17.7 \%$ consider themselves absolutely healthy, $20.8 \%$ are almost healthy, $61.5 \%$ are not very healthy. Most of the interviewers had various psychosomatic complaints: headaches $(54.8 \%$ ), abdominal pain $(51.6 \%)$, fatigue $(48.4 \%)$, irritability $(45.1 \%)$, dizziness $(41.9 \%)$, bad $\operatorname{mood}(38.7 \%)$.

Conclusion: It has been revealed that among teenagers with visual impairments the common factors are hard heredity, somatic symptom disorder, lack or insufficiency of solar insolation, inappropriate illumination of the workplace, a sedentary lifestyle and intense visual stress.

The survey showed that young people with myopia are underweight.

To study the features of vegetative regulation in teenagers with myopia, we conducted cardiointervalography. The vegetative nervous system ensures the maintenance of homeostasis, as well as the normal regulation of the work of all organs and systems of the body. At the same time, the cardiovascular system is one of the fastest responding to changes in the body's balance with the environment [9]. It is the cardiovascular system that is considered as a universal indicator of all pathological processes, reflecting the state of regulatory mechanisms and adaptive capabilities of the body [10]. During the study, the main indicators of cardiointervalometry were analyzed: variation range of intervals $(\mathrm{X}, \mathrm{s})$, average interval $(\mathrm{M}, \mathrm{s})$, mode (MO, s), mode amplitude (AMO, \%), voltage index of regulatory systems (VI, conventional units).

The determination of the initial vegetative tone revealed that in adolescents of the main and control groups, sympathicotonia is the predominant tone of the autonomic nervous system, while sympathicotonia is more common in young men with myopias $-57.4 \%$. Among girls with myopia, sympathetic tone (sympathicotonus) is also the predominant tone of the autonomic nervous system $-46.1 \%$.

Table 2. Characteristics of initial vegetative tone of teenagers

\begin{tabular}{|c|c|c|c|c|}
\hline \multirow{2}{*}{ Vegetativetonus } & \multicolumn{2}{|c|}{$\begin{array}{c}\text { Main } \\
\text { group, \% }\end{array}$} & \multicolumn{2}{c|}{ Control group, \% } \\
\cline { 2 - 5 } & girls & boys & girls & boys \\
\hline vagotonics & 24.6 & 13.1 & 34.2 & 31.3 \\
\hline eutonics & 29.3 & 29.5 & 20.5 & 30.0 \\
\hline sympathotony & 46.1 & 57.4 & 45.3 & 38.7 \\
\hline
\end{tabular}


Table 3 shows the main parameters of cardiointervalometry.

Table 3. Cardiointervalometry indicators

\begin{tabular}{|l|l|l|l|l|}
\hline \multirow{2}{*}{ Indicators } & Main group & \multicolumn{2}{l|}{ Control group } \\
\cline { 2 - 5 } & girls & boys & girls & boys \\
\hline Variationspan (X, sec) & $0.25 \pm 0.02$ & $0.19 \pm 0.01^{*}$ & $0.26 \pm 0.01$ & $0.25 \pm 0.01$ \\
\hline Averageinterval (M, sec) & $0.76 \pm 0.01$ & $0.70 \pm 0.01^{*}$ & $0.80 \pm 0.01$ & $0.79 \pm 0.01$ \\
\hline Mode (sec) & $0.76 \pm 0.01$ & $0.70 \pm 0.01$ & $0.79 \pm 0.01$ & $0.74 \pm 0.01$ \\
\hline modeamplitude (\%) & $43.35 \pm 2.22$ & $48.55 \pm 2.41$ & $43.00 \pm 1.59$ & $43.10 \pm 1.37$ \\
\hline stressindex (c.u) & $188.08 \pm 31.5$ & $224.72 \pm 51.9$ & $172.20 \pm 16.5$ & $172.92 \pm 14.7$ \\
\hline heartrate, sec & $79.88 \pm 1.33$ & $84.16 \pm 1.5^{*}$ & $76.97 \pm 1.17$ & $77.25 \pm 0.80$ \\
\hline SDNN,sec & $0.055 \pm 0.004$ & $0.041 \pm 0.002$ & $0.053 \pm 0.003$ & $0.060 \pm 0.007$ \\
\hline RMSSD, sec & $0.055 \pm 0.005$ & $0.032 \pm 0.002$ & $0.056 \pm 0.003$ & $0.053 \pm 0.002$ \\
\hline *p $<0.05$ & & &
\end{tabular}

The indicator of variation span $(0.15-0.30)$ and mode amplitude (normal 31-49) in all teenagers corresponds to eutonics. The stress index (normal 51-199) in young men with myopias goes beyond the boundaries of eutonics, which reflects an increase in sympathetic regulation, the stress of the functioning of the system and confirms the predominance of sympathicotony. The relatively high Mo rate in teenagers of both genders and groups indicates a high level of exposure to humoral factors. Such mechanisms of heart regulation are imperfect and pose a risk of overstress and failure of adaptation.

In young men with myopias, the maximum value of SDNN (mean square deviation) was 0.041, the value of the RMSSD indicator was 0.032. Thus, we can talk about a decrease in parasympathetic activity in young men with impaired refraction.

Measures of spectral analysis of heart rate variability in teenagers were also studied. The results are shown in Table 4.

Table 4. Spectral analysis indicators

\begin{tabular}{|l|l|l|l|l|}
\hline \multirow{2}{*}{ Indicators } & Main group & \multicolumn{2}{l|}{ Control group } \\
\cline { 2 - 5 } & girls & boys & & girls \\
\hline HF & $1108.78 \pm 187.69$ & $858.06 \pm 375.0$ & $1231.29 \pm 196.81$ & $1158.39 \pm 133.79$ \\
\hline LF & $1979.47 \pm 376.38$ & $3009.79 \pm 801.5$ & $1561.65 \pm 144.34$ & $1932.57 \pm 145.59$ \\
\hline VLF & $2485.98 \pm 300.21$ & $3968.06 \pm 1795.02$ & $1780.99 \pm 142.24$ & $2515.09 \pm 207.01$ \\
\hline LF/HF & $2.46 \pm 0.22$ & $3.33 \pm 0.36$ & $2.28 \pm 0.16$ & $2.89 \pm 0.34$ \\
\hline TF & $5574.2 \pm 780.9$ & $7835.9 \pm 3954.8$ & $4528.8 \pm 419.9$ & $5614.1 \pm 404.3$ \\
\hline
\end{tabular}

Analysis of the results showed that the value of the high-frequency spectrum ( $\mathrm{HF} 0,15,4 \mathrm{~Hz}$ ), reflecting respiratory arrhythmia and vagus heart rate control, is higher in girls of the control group $-1231.29 \pm 196.81$, and in young men of the control group $-1158.39 \pm 133.79$. The calculated component of the indicator of low-frequency oscillations (LF 0.04-0.15 Hz), which is of mixed origin and is associated with both vagus and sympathetic control of heart rhythm, higher in boys with myopias $3009.79 \pm 801.5$, and in girls with myopias $-1979.47 \pm$ 376.38. The value of the VLF indicator (power of ultralow-frequency oscillations of the heart rhythm $<0.04$ $\mathrm{Hz}$ ), reflecting the activity of the suprasegmental level of the autonomic nervous system, was higher in young men with myopias $-3968.06 \pm 795.02$.

Indicator of activity of regulatory systems (LARS = $\mathrm{AMo} / \mathrm{Mo}$ - allows assess the degree of functional stress and overload in teenagers. We have found that $39.4 \%$ of teenagers with myopia have functional stress, they are characterized by insufficient protective-adaptive mechanisms and inability to adequately respond to environmental factors [3, 4].
Functional reserves of the adolescent body were determined taking into account the dynamics of parameters of cardiac rhythm variability during a loading test (active orthostatic test).

The adequate response of the cardiovascular system to the orthostatic test was determined only in $55.1 \%$ of boys and in $44.2 \%$ of girls from the main group. An increased and significantly increased cardiovascular response was determined in $26.2 \%$ of boys and in $41.2 \%$ of girls from the main group. In the control group, an increased and significantly increased cardiovascular response was determined in $20.0 \%$ of boys and $33.3 \%$ of girls.

The diagnostic algorithm of our program evaluates vegetative support by the consistency of changes in the static parameters of MxDMn and AMo. Sufficient vegetative support occurs only in $35.4 \%$, excessive and extremely excessive provision occurs in $35.1 \%$, insufficient provision in $12.9 \%$, paradoxical provision in $16,6 \%$ of teenagers with myopia. 
Table 5. Conclusion to orthostatic test reaction

\begin{tabular}{|l|l|l|l|l|}
\hline Assessment of the & \multicolumn{3}{|l|}{ Main group, \% } & \multicolumn{2}{l|}{ Control group, \% } \\
\cline { 2 - 5 } transition process & girls & boys & girls & boys \\
\hline $\begin{array}{l}\text { Normal transition } \\
\text { process. Adequate } \\
\text { cardiovascular } \\
\text { response to } \\
\text { orthoprobe }\end{array}$ & 44.2 & 55.1 & 49.4 & 63.9 \\
\hline $\begin{array}{l}\text { Increasedcardiovasc } \\
\text { ularresponse }\end{array}$ & 34.2 & 14.2 & 29.2 & 15.7 \\
\hline $\begin{array}{l}\text { Significantlyincrease } \\
\text { dreaction }\end{array}$ & 7.0 & 12.0 & 4.1 & 4.3 \\
\hline $\begin{array}{l}\text { Reducedorthoprober } \\
\text { esponse }\end{array}$ & 6.8 & 8.5 & 9.4 & 8.6 \\
\hline $\begin{array}{l}\text { Orthoprobereactionn } \\
\text { otdetermined }\end{array}$ & 7.7 & 10.1 & 7.8 & 7.4 \\
\hline
\end{tabular}

According to the results of the Cardio Expert computer cardiorhythmography complex, a satisfactory adaptation was observed in $12.2 \%$ of boys and $24.6 \%$ of girls, tension of adaptation mechanisms was observed in $63.3 \%$ of boys and $50.8 \%$ of girls, unsatisfactory adaptation was observed in $24.5 \%$ of boys and $24.5 \%$ of girls from the main group. In the control group, satisfactory adaptation occurs more often: among girls $39.3 \%$, among boys $-31.3 \%$.

Table 6. Functional state of teenagers

\begin{tabular}{|l|l|l|l|l|}
\hline \multirow{2}{*}{ Functionalstate } & \multicolumn{3}{|l|}{ Main group, \% } & \multicolumn{2}{l|}{ Control roup, \% } \\
\cline { 2 - 5 } & girls & boys & girls & boys \\
\hline $\begin{array}{l}\text { Satisfactory } \\
\text { adaptation }\end{array}$ & 24.6 & 12.2 & 39.3 & 31.3 \\
\hline $\begin{array}{l}\text { Tension Adaptation } \\
\text { mechanisms }\end{array}$ & 50.8 & 63.3 & 41.2 & 50.9 \\
\hline $\begin{array}{l}\text { Unsatisfactory } \\
\text { adaptation }\end{array}$ & 24.6 & 24.5 & 19.5 & 17.8 \\
\hline
\end{tabular}

\section{CONCLUSIONS}

It has been revealed that among teenagers with visual impairments the common factors are hard heredity, somatic symptom disorder, lack or insufficiency of solar insolation, inappropriate illumination of the workplace, a sedentary lifestyle and intense visual stress.

According to cardiorhythmography, teenagers with myopia have a high level of centralization of heart rate management, a relatively high level of activity of the sympathetic department of the autonomic nervous system and low activity indicators of the parasympathetic department of the autonomic nervous system. In young men, sympathicotonia was much more common than in girls. Sympathicotonia, functional tension and overload, increased cardiovascular response to orthostatic test, excessive and insufficient, and paradoxical vegetative provision are characteristic of teenagers with myopia.
The results showed that teenagers with myopia of both genders have of the autonomic nervous system imbalance.

\section{REFERENCES}

[1] P.J. Foster, Y. Jiang, Eye (Lond) 28(2) (2014).

[2] I.G. Morgan, A.N. French, R.S. Ashby et al., Prog. Retin. Eye Res. 62(1) (2018).

[3] C. Wolfram, R. Höhn, U. Kottler et al., Br. J. Ophthalmol. 98(7) (2014).

[4] O.V. Proskurina, E.Y. Markova, V.V. Brzheskij et al., The Ophthalmol. in Rus. 15(3) (2018).

[5] E.P. Tarutta, O.V. Proskurina, N.A. Tarasova, G.A. Markosyan, Health Risk Anal. 3 (2019).

[6] B.A. Holden, T.R. Fricke, D.A. Wilson et al., Ophthalmol. 123(5) (2016).

[7] E.M. Iomdna, E.P. Tarutta, Ann. of the Rus. Acad. of med. sci. 69(3-4) (2014).

[8] A.E. Aprelev, N.P. Setko, R.V. Pashinina et al., Bashkor. Med. J. 11(1(61)) (2016).

[9] E.P. Timofeeva, T.I. Ryabichenko, G.A. Skosyreva, T.V. Kartseva, Rus. Bull. of perinatal. and pediatr. 61(4) (2016).

[10] R.M. Baevsky, G.G. Ivanov, A.P. Gavrilushkin et al., J. of Arrhythmol. 24 (2002). 